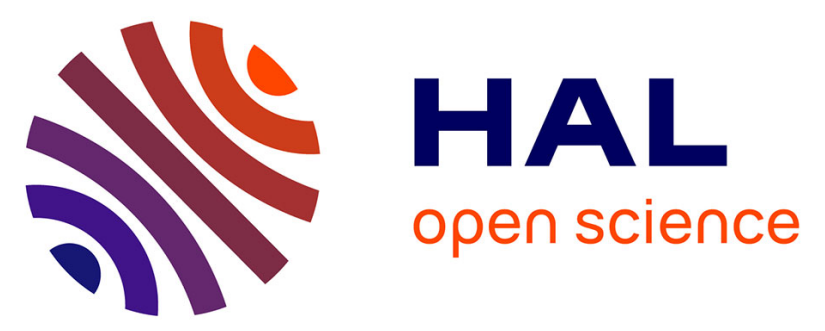

\title{
Polycystins and intercellular mechanotransduction: A precise dosage of polycystin 2 is necessary for alpha-actinin reinforcement of junctions upon mechanical stimulation
}

Laxsoomee Bhoonderowa, Fatima Hameurlaine, Atousa Arbabian, Fahima

Faqir, François Amblard, Sylvie Coscoy

\section{To cite this version:}

Laxsoomee Bhoonderowa, Fatima Hameurlaine, Atousa Arbabian, Fahima Faqir, François Amblard, et al.. Polycystins and intercellular mechanotransduction: A precise dosage of polycystin 2 is necessary for alpha-actinin reinforcement of junctions upon mechanical stimulation. Experimental Cell Research, 2016, 348 (1), pp.23-35. 10.1016/j.yexcr.2016.08.021 . hal-01366459

\section{HAL Id: hal-01366459 \\ https://hal.sorbonne-universite.fr/hal-01366459}

Submitted on 14 Sep 2016

HAL is a multi-disciplinary open access archive for the deposit and dissemination of scientific research documents, whether they are published or not. The documents may come from teaching and research institutions in France or abroad, or from public or private research centers.
L'archive ouverte pluridisciplinaire HAL, est destinée au dépôt et à la diffusion de documents scientifiques de niveau recherche, publiés ou non, émanant des établissements d'enseignement et de recherche français ou étrangers, des laboratoires publics ou privés. 


\title{
ACCEPTED MANUSCRIPT
}

Polycystins and intercellular mechanotransduction: a precise dosage of polycystin 2 is necessary for alpha-actinin reinforcement of junctions upon mechanical stimulation

Laxsoomee Bhoonderowa $^{1,2}$, Fatima Hameurlaine ${ }^{1,2}$, Atousa Arbabian ${ }^{1,2}$, Fahima Faqiir ${ }^{1,2}$, François

$$
\text { Amblard }^{1,2}, \text { Sylvie Coscoy }{ }^{1,2^{*}}
$$

${ }^{1}$ Laboratoire Physico Chimie Curie, Institut Curie, PSL Research University, CNRS UMR 168, 75005, Paris, France

${ }^{2}$ Sorbonne Universités, UPMC University Paris 06, 75005, Paris, France.

"Corresponding author : Sylvie.Coscoy@curie.fr

\begin{abstract}
Polycystins 1 and 2, which are mutated in Autosomal Polycystic Kidney Disease, are involved in mechanotransduction through various mechanisms. In renal cells, polycystins not only have an important mechanotransductive role in primary cilia but are also present in intercellular contacts but their role there remains unclear. Here, we address the hypothesis that polycystins are involved in mechanotransduction via intercellular junctions, which would be expected to have consequences on tissue organization. We focused on the role of polycystin 2 , which could be involved in mechanical organization at junctions either by its channel activity or by the direct recruitment of cytoskeleton components such as the F-actin cross-linker $\alpha$-actinin. After mechanical stimulation of intercellular junctions in MDCK renal epithelial cells, $\alpha$-actinin is rapidly recruited but this is inhibited upon overexpression of PC2 or the D509V mutant that lacks channel activity, and is also decreased upon PC2 silencing. This suggests that a precise dosage of PC2 is necessary for an adequate mechanosensitive $\alpha$-actinin recruitment at junctions. At the multicellular level, a change in PC2 expression was associated with changes in velocity in confluent epithelia and during wound healing together with a loss of orientation. This study suggests that the mechanosensitive regulation of cytoskeleton by polycystins in intercellular contacts may be important in the context of ADPKD.
\end{abstract}

Keywords

Polycystin; Alpha-actinin; Cytoskeleton; Mechanotransduction; Cell junction; Epithelial cells; Ion channel 


\section{ACCEPTED MANUSCRIPT}

\section{Introduction}

Epithelia form highly cohesive structures with intercellular contacts, such as adherens junctions, tight junctions and desmosomes, that need to be tightly regulated so that cell-cell adhesion is maintained despite fluctuations in the forces that originate from each cell. At a higher time-scale, this regulation allows the morphological and functional adaptation of the epithelia to mechanical stress arising from the environment or morphogenetic movements. In adherens junctions, homophilic contacts between cells are ensured by E-cadherins, which are indirectly coupled to the F-actin cytoskeleton through $\beta$-catenin/ $\alpha$-catenin links (1-2) with F-actin bundles cross-linked primarily by vinculin and $\alpha$-actinin. Adherens junctions experience forces originating from neighboring cells due to either the contraction of actomyosin at steady-state or the reorganization (e.g. division) of these adjacent cells (3). Mechanotransduction in junctions relies on a strong interconnection between the cadherin/catenin system and the acto-myosin system, with $\alpha$-catenin-vinculin as a central functional module. The application of a force causes $\alpha$-catenin to stretch, which leads to the exposure of a cryptic site and its binding to actin-bundling proteins, in particular vinculin (4-9) or $\alpha$-actinin as more recently described (4). The recruitment of these complexes reinforces cell-cell junctions, due to either the bundling activity of vinculin/ $\alpha$-actinin or the subsequent recruitment of other factors that remodel the actin cytoskeleton such as zyxin, vasodilator-stimulated phosphoprotein (VASP) or Arp2/3 (5).

The aim of this study is to address whether putative mechanosensitive channels are also important for mechanotransduction in intercellular contacts. Interestingly, cation transient receptor potential (TRP) channels (6-7) are involved in mechanotransduction in focal contacts: the ultra-fast activation of mechanosensitive TRPV4 channels by integrins in endothelial cells leads in a retroactive loop to additional integrin recruitment, and mediates cyclic strain-induced endothelial reorientation (8). Some TRP channels have been reported to be both mechanosensitive and present at intercellular contacts: in particular, complexes comprising polycystin 1 (PC1) and polycystin 2 (PC2). The mechanosensitivity of polycystins in the primary cilia strongly suggests a similar role in adherens junctions, where they are found within a complex with cadherins and catenins (9). 
PC1 and PC2 are mutated in the most common renal genetic disease Autosomal Dominant Polycystic Kidney Disease (ADPKD), which leads not only to progressive renal insufficiency in adulthood as a result of the development of numerous renal cysts, but also in the disorganization of other tissues (e.g. hepatic cysts, cerebral aneurysms). PC2 is a cation non-selective TRP channel with a complex gating mechanism that is dependent on phosphatidylinositol 4,5bisphosphate $\left(\mathrm{PIP}_{2}\right)$ binding and interactions with protein partners, and has been reported to be mechanically gated in some cellular systems. PC2 can form a complex with PC1, a transmembrane protein comprising a very large extracellular loop with multiple functional domains (10). PC1 and PC2 are present in a variety of subcellular localizations (in particular, primary cilia, intercellular and basal contacts and, for PC2, the endoplasmic reticulum) where they establish links with numerous cytoskeleton and adhesion proteins. For example, PC1 forms complexes with $\alpha 2 \beta 1$ integrin, tropomyosin, troponin 1 , talin, vinculin and $\alpha$-actinin at focal contacts (11). PC2 binds to mDia, a Rho GTPase effector protein (15), and to the F-actin cross-linker $\alpha$-actinin (16). Polycystins are also coupled to several signaling pathways (mTOR, JAK/STAT, PI3K/Akt, G proteins). In vitro loss-of-function or the overexpression of polycystins have major effects on tissue organization including proliferation, apoptosis, tubulogenesis, planar polarity and the control of cell size (17-21).

The response of the polycystin complex to mechanical stimuli involves very different mechanisms depending on the cellular system (22). In primary cilia of renal epithelial cells, the bending of primary cilia induced by extracellular flow was classically proposed to lead to direct calcium entry, requiring both PC1 and PC2 possibly acting as a "primary mechanosensor" (23). However, this role for calcium-responsive mechanosensing by primary cilia has recently been debated (24): a detailed imaging analysis with high temporal resolution suggested that physiological or supraphysiological mechanical stimuli (bending of cilia with flow) did not elicit a fast calcium response in cilia, which is in contrast with the prevailing view. Polycystins might thus have 


\section{ACCEPTED MANUSCRIPT}

another mechanosensitive role in cilia that is not linked to PC2 channel function; alternatively, they could have a mechanosensory role in other cell substructures, related (or not) to their channel activity. (Indeed in cilia, a slow increase of calcium influx from the cytoplasm was observed after 10-20 s of mechanical stimulation (24)). On the other hand, an entirely different mechanism for the mechanosensitive properties of the polycystin complex was reported in vascular smooth muscle, in which the PC1/2 ratio was shown to determine pressure sensing: stretch-activated channels are inhibited by PC2 via its effects on cytoskeletal organization (filamin), and PC1 releases this inhibition (25). Polycystins have also been implicated in bone development and mechanosensing (26-28). It is thought that the tissue defects observed in ADPKD kidneys might result from aberrant mechanosensing. In healthy tissue, some signaling pathways (such as mTOR, STAT6) are activated only in situations such as wound healing, which generate abnormal flow and would be detected by bending of the primary cilia through the mechanosensory role of polycystins. However in ADPKD, the defective mechanosensitive behaviour of polycystins would lead to constitutive activation of these pathways (29).

We hypothesized that the mechanosensor activity of polycystins is not only important in primary cilia, but also in intercellular contacts. PC1 is present in tight junctions but is even more abundant in adherens junctions and in desmosomes where it associates with intermediate filaments. In renal tissue, $\mathrm{PC} 1$ is present in a complex containing E-cadherin and $\alpha-, \beta$ - and $\gamma$-catenins (9), and it can bind to cytoskeleton proteins such as mDia, vinculin and $\alpha$-actinin. This link with cadherin is physiologically important because in ADPKD renal epithelium, E-cadherin is improperly sequestered in intracellular pools (30) and shows an increased shedding (31). PC1 accelerates the recruitment of E-cadherin to reforming cell-cell contacts in $\mathrm{Ca}^{2+}$ switch experiments in MDCK cells (32). The overexpression of PC1 in MDCK cells leads to a scattered morphology with actin reorganization and an increased migration, altered behavior in wound-healing experiments, and a decrease in cell-cell adhesion in confluent monolayers (33). Therefore, PC1 seems to have a key role in the adhesive properties of epithelia. The role of PC2 is less well documented; interestingly, in MDCK cells it is localized at lateral junctions only in confluent or near-confluent cells, and its 


\section{ACCEPTED MANUSCRIPT}

localization between the membrane and the cytoplasm is reorganized during wound-healing experiments (34).

PC2 could be important in intercellular contacts because of its ability to either form a mechanosensitive channel or recruit cytoskeleton molecules. In this study, we specifically focused on the link between PC2 and $\alpha$-actinin, which is present in adherens junctions and has been shown to bind to PC2 and modulate its activity (16). $\alpha$-actinins belong to the spectrin family and are abundant in muscle (isoforms 2,3) and non-muscle cells (isoforms 1, 4). They comprise an Nterminal actin-binding domain, a central domain with spectrin-like repeats (which can bind to $\alpha$ catenin and vinculin, and is sufficient for junctional targeting (35)) and a C-terminal calmodulinlike domain with 2 EF-hands (that confers calcium and phosphoinositide regulation) (36). Ubiquitous isoforms 1 and 4 are involved in calcium-dependent membrane attachment in adherens junctions and focal contacts: two identical molecules associate in a head-to-tail manner to bundle F-actin filaments, and calcium binding leads to the release of an actin monomer from their actinbinding domain. $\alpha$-actinin also binds to some phospholipids, leading to a decrease in its F-actin bundling activity through competition (37-39). Finally, $\alpha$-actinin interacts with a number of cytoskeletal and membrane proteins, including zyxin (40), integrins (41), catenins (42), the NMDA receptor (43), Kv channels (38) as well as PC2 (16). Both the N-terminal domain (residues 1-215) and the C-terminal domain (residues 821-878) of PC2 bind to $\alpha$-actinin (isoforms 1 and 2) in a calcium-independent manner (16). These domains directly contact the spectrin repeats and the Cterminal part of $\alpha$-actinin but not its $\mathrm{N}$-terminal actin-binding domain (16). The direct interaction between these two proteins has a functional effect because in lipid bilayers with reconstituted PC2, $\alpha$-actinin overexpression strongly increases single channel currents (16) in a calcium-dependent manner (44).

Similar to other cytoskeletal proteins such as vinculin and paxillin, $\alpha$-actinin is recruited upon mechanical stimulation of focal contacts. This recruitment is dependent on zyxin targeting to stress 


\section{ACCEPTED MANUSCRIPT}

fibers and is crucial for actin remodeling (45-46). The kinetics of $\alpha$-actinin binding was recently shown to be involved in cell dynamics and force generation (47). At a multicellular level, changes in $\alpha$-actinin levels are associated with changes in motility and invasive capacities, and have been linked to a variety of cancers (48-52).

The role of $\alpha$-actinin mechanosensing during junction maturation has recently been studied (4). A mechanical force induced actin- and $\alpha$-actinin- 4 accumulation at junctions in a time- and tension-dependent manner, and $\alpha$-actinin- 4 was needed for subsequent vinculin recruitment. An upstream regulator of $\alpha$-actinin recruitment, synaptopodin, was also identified. Synaptopodin is a protein composed of three modules: one that is responsive to tension, one that is responsible for junctional complex formation, and one that forms a complex with myosin II. Synaptopodin accumulates at junctions at the beginning of maturation, resulting in subsequent $\alpha$-actinin- 4 and then vinculin accumulation, and is also involved in Akt S473 phosphorylation upon mechanical stimulation (4).

We address here the hypotheses that polycystins have a role in mechanotransduction in intercellular contacts through their channel and/or cytoskeleton recruitment functions and that consequently, polycystins are involved in the regulation of intercellular forces between cells and, ultimately, multicellular dynamic organization. 


\section{ACCEPTED MANUSCRIPT}

Experimental procedures

Molecular biology

Plasmids human PC2 in pIRES-RFP, human PC2 D509V in pIRES-GFP, HA-mPC2-WT in pCDNA3.1, HA-PC2-742X- $\Delta$ Nter(1-203) and HA-PC2-813X-ANter(1-203) in pCDNA3.1 were a kind gift from Eric Honoré and Amanda Patel, and $\alpha$-actinin 1 in pEGFP-N1 from Carol Otey (53). For shRNA constructs, pSIRNA-h7SK (Zeo) from Invivogen (San Diego) as modified by Monique Arpin and Laurence del Maestro in order to incorporate the mCherry coding sequence. Different shRNA sequences targeting canine PC2 were integrated in the vector (21 nt oligonucleotides starting respectively in positions 416, 805, 1221, 1413, 1784 and 2371 of canine PC2 sequence). shRNA constructs used in this study were chosen based on the decrease in PC2 immunofluorescent labeling after transfection in MDCK cells. The construct 1221 (sense oligonucleotide 5, ACCTCGAGTCAGCTCTCCACAACTATTCAAGAGATAGTTGTGGAGAGCTGACTCTT 3’) gave a net decrease in PC2 labeling, and is referred to here as PC2 siRNA (si-PC2). Results were compared with scrambled siRNA (scr) in the same pSIRNA-Cherry plasmid, kindly provided by Laurence del Maestro and Monique Arpin (5' ACCTCGATATGTGCGTACCTAGCATTCAAGAGATGCTAGGTACGCACATATTT 3’).

Cell culture and transfections

MDCK cells (CCL-34, LGC Promochem) were maintained at $37^{\circ} \mathrm{C}$ and $5 \% \mathrm{CO}_{2}$ in $\mathrm{DMEM}+10 \%$ SVF, plus $0.4 \mathrm{mg} / \mathrm{ml}$ geneticin for stable clones. E-cadherin-GFP cells were a kind gift of WJ Nelson. Cells were transfected with a BioRad electroporator. For stable transfections, MDCK clones overexpressing PC2 were selected with geneticin, amplified, and selected according to the subcellular localization and level of PC2 immunofluorescence labeling. MDCK stably transfected with Life-ActGFP and vinculin-GFP were gifts respectively of O. Cochet/ P. Silberzan and W.J. Nelson. siRNA- or scr-transfected cells were selected 2 days after transient transfection by flow cytometry based on their mCherry labeling, plated and studied the following day, unless otherwise specified: cell sorting was not performed for the experiments involving stimulation of intercellular junction on si/scr cells (SI) 


\section{ACCEPTED MANUSCRIPT}

because the low number of cells would not have allowed confluency in a large area $(30 \mathrm{~mm}$ coverslip), which was crucial for these experiments (see "mechanical stimulation").

\section{Antibodies and reagents}

Antibodies used were anti-PC2 (Santa Cruz, G-20, sc-10376), anti-PC1 (Santa Cruz, C-20, sc-10372), anti-alpha-actinin (abcam, ab11007), anti- $\gamma$-tubulin (GTU-88, Sigma Aldrich), anti-HA (7-12CA5 clone, Institut Curie's platform for recombinant proteins), and anti-pericentrine (clone PRB-432C). Secondary antibodies (anti-goat Alexa 488, anti-goat Alexa 555, anti-mouse Alexa 488, anti-mouse Alexa 555) were from Invitrogen. Probenecid, gadolinium, lanthanum chloride, lithium chloride, LY294002 and phalloidin-TRITC and Hoechst were purchased from Sigma, Fluo4-AM from Molecular Probes, pluronic acid from Invitrogen.

\section{Immunofluorescence, Western blots}

For immunofluorescence, cells were fixed with $4 \%$ paraformaldehyde and permeabilized for 4 min in PBS-0.1\% TritonX100 for anti- $\alpha$-actinin antibody, or fixed with $-20^{\circ} \mathrm{C}$ methanol for anti-polycystin antibodies. For Western blots, cells were resuspended in $50 \mathrm{mM}$ Tris $\mathrm{pH} 7.4,20 \mathrm{mM} \mathrm{KCl}$, and protease inhibitors, the lysate was syringed and incubated for 15 min with DNase I at $37^{\circ} \mathrm{C}$. Anti-PC antibodies were diluted 1/50 for immunofluorescence and 1/500 for Western blots, anti- $\alpha$-actinine antibody 1/200 for immunofluorescence and 1/500 for Western blots. Blot images were acquired and analyzed with ImageLab and ImageJ. A normalization with total protein content as determined by Ponceau staining was performed.

Migration and wound-healing assays

Migration/wound-healing assays were performed as previously described in Poujade et al. (54), or in Ibidi culture inserts according to the manufacturer's instructions, with similar results. Analyses presented in Fig. 4 correspond to experiments performed in Ibidi inserts. In these inserts, $100 \mu$ of cells at $\sim 10^{6}$ cells $/ \mathrm{ml}$ were seeded on each well, on Ibidi's micro-Dish $35 \mathrm{~mm}$ high, tissue-culture 


\section{ACCEPTED MANUSCRIPT}

treated. After culturing for $24 \mathrm{~h}$, cells were at confluence, and Ibidi culture inserts were removed and observed by videomicroscopy.

\section{Calcium probe}

Cells were loaded for $15 \mathrm{~min}$ at $37^{\circ} \mathrm{C}$ with the calcium probe Fluo4-AM (in $1 \mathrm{ml}$ medium $+5 \mu \mathrm{g}$ Fluo $4+1 \mu$ pluronic acid $+2.5 \mathrm{mM}$ probenecid $+10 \mathrm{mM}$ Hepes $\mathrm{pH}$ 7.4) and rinsed for $30 \mathrm{~min}$ in medium + probenecid + Hepes. The observation was done at $37^{\circ} \mathrm{C}$, in medium + probenecid + Hepes (see "mechanical stimulation" for observation conditions).

\section{Estimation of cell size and orientation}

For estimations of cell length, we measured cell major axes after image acquisition, in epifluorescence or bright-field microscopy. Because cell dimensions, including cell length, strongly depend on cell confluency, the comparisons were always made in cells seeded the same day at the same density. The orientation of cell displacement in wound-healing experiments was performed using Particle Image Velocimetry (AVeMap) (55), a rapid, fully automated correlation-based method for cell migration analysis with an extensive dynamic mapping of cell displacements (available on August 2016 on http://umr168.curie.fr/fr/quipes-de-recherche/physico-biologie-aux-m-sochelles/avemap/avemap-003041).

\section{Observation}

Videomicroscopy was realized on a Nikon set-up, with an Eclipse Ti inverted microscope, a Coolsnap HQ2 camera, and a Perfect Focus System z correction, at $37^{\circ} \mathrm{C}$ and $5 \% \mathrm{CO}_{2}$, on cells in Ibidi $35 \mathrm{~mm}$ high tissue-culture treated dishes. For junction movements, comparisons were systematically performed between cultures in the same confluence conditions. Confocal imaging was performed on a Nikon A1R or Leica SP2 AOBSs. Videomicroscopy for junction movement analysis and confocal imaging were performed on workstations of the Nikon Imaging Center (Institut Curie, CNRS) and of the PICT-IbiSA Lhomond Imaging facility of the Institut Curie. 


\section{ACCEPTED MANUSCRIPT}

Two-photon fluorescence recovery after photobleaching (FRAP)

Two-photon FRAP experiments were performed as previously described (56-57). Briefly, experiments were performed at $37^{\circ} \mathrm{C}$ on an IX71 inverted microscope with a $63 \mathrm{X}$ objective (NA1.25), two-photon photobleaching was performed with a femto-second laser tuned at $878 \mathrm{~nm}$, pumped by a 10W CW $532 \mathrm{~nm}$ laser (Mira 900 and Verdi;Coherent), and fluorescence recovery was followed with fast 3D videomicroscopy. Points selected near the center of $\alpha$-actinin-GFP-expressing junctions were photobleached for $200 \mathrm{~ms}$ for each point (20 mW power). 3D acquisitions for recovery analysis were performed every second (with a $\Delta \mathrm{z}$ of $0.3 \mu \mathrm{m}$ ), from $7 \mathrm{~s}$ before photobleaching to $5 \mathrm{~min}$ after. Analyses were performed on a home-made Matlab program, integrating corrections for observational photobleaching and junction movements.

\section{Mechanical stimulation}

For mechanical stimulation experiments, we used cells on $30 \mathrm{~mm}$ glass coverslips, either labeled with a fluorescent protein or loaded with a calcium probe. Coverslips were mounted on a $37^{\circ} \mathrm{C}$ observation chamber in medium +10 mM Hepes pH7,4 (POC-mini chamber system, Tempcontrol 37-2 Digital Pecon) on an IX70 inverted microscope (Olympus), with 40X objective (UPlanSApo, Olympus, NA0.9, mainly used for calcium experiments, ) and 100X objective (UPlanSApo, Olympus, NA1.4, mainly used for cytoskeleton experiments), connected to a camera (CoolSnap HQ2, Photometrics) controlled by MicroManager. Borosilicate glass capillaries (OD $1.5 \mathrm{~mm}$, ID $0.84 \mathrm{~mm}$, World Precision Instruments) were pulled (Sutter Instrument P-2000), microforged so that their end was smooth and 1-2 $\mu \mathrm{m}$ in width (microforge Narishige MF-830), and manipulated with a MP-285 micromanipulator (Sutter Instrument). The micropipette contacted the cell near (but not on) a junction, pushed the junction perpendicularly with a displacement of about $2 \mu \mathrm{m}(1-3 \mu \mathrm{m})$, maintained this position for a few seconds and was then released. (Experiments with displacements higher than $4 \mu \mathrm{m}$ were discarded). Typically, images were acquired with a time interval of $300 \mathrm{~ms}$ for an observation duration of $120 \mathrm{~s}$ per acquisition, in which a few different stimulations were performed 


\section{ACCEPTED MANUSCRIPT}

on different cells. We checked that contacted cells did not show major perturbations following the experiments (as shown by the conservation of the calcium/cytoskeleton labeling), otherwise the experiment was discarded. For si/scr experiments, the results reported correspond to conditions in which cells were not sorted, so that the monolayer was at confluence 2 days after transfection, and only junctions between two red cells were stimulated (transfection efficiency 30\%).

Push or pull experiments were performed, which correspond to different physical mechanisms (concerning the effect on cadherins), although both lead to an increase in the calcium/cytoskeleton reinforcement signal, possibly because of direct sensing by actomyosin bundles (58). Data and statistics shown correspond to "push" actions, for which a striking difference in $\alpha$-actinin recruitment following stimulation was observed in our preliminary experiments.

\section{Image treatment and analyses}

Mechanical stimulation analysis was performed on ImageJ or Metamorph. For intercellular calcium wave experiments, the width of the maximal region with increased intracellular calcium concentration was measured manually. For cytoskeleton recruitment, the mean intensity was followed on a small region (typically 2-3 $\mu \mathrm{m}$ length) on the junction (or in cytoskeletal or adjacent junctions for control), with manual adaptation to junction displacement; the junction displacement was systematically measured in parallel (with no correlation observed between displacement and mean stimulation in the range of 1-3 $\mu \mathrm{m}$, not shown). Data were reported in Kaleidagraph, after the subtraction of camera background. Analysis of two-photon experiments was performed as previously described, on a homemade Matlab program (Mathworks) (56). Particle Image Velocimetry analysis was performed using AVeMap (55). Junction displacements on confluent cells were measured after exclusion around areas where a cell division or an apoptosis were observed, by superimposition of images acquired between the time interval of interest and the measurement of perpendicular displacement, thanks to perpendicular profile analysis allowing precision for small displacements. Relative quantification of PC2 levels on si-PC2 and scr immunofluorescence images (Fig. 1g) was performed after transient transfection and 2 days plating between groups of transfected cells (red labeling) and groups of 


\section{ACCEPTED MANUSCRIPT}

control cells in the same coverslip, corresponding to identical conditions of PC2 immunofluorescence

(green labeling). Total (green) signal in each group, signal in basal bodies, and signal integrated along intercellular junctions, were measured with ImageJ and statistically compared. Statistics: the indicated errors are standard errors of the mean (SEM). Statistical tests were performed with Excell Analysis Tools: first, F-Tests were realized to test assumptions of equal or unequal variances of two sets of data; second, the corresponding T-tests were performed. Images shown on figures were denoised for representation using ImageJ ND-Safir plugin (59) or smoothed with ImageJ software. 
Results

1 - Characterization of MDCK cells with altered polycystin 2 expression

To study the role of PC2 in intercellular contacts, we generated MDCK cell lines with altered PC2 levels and studied their behavior before the onset of primary cilia. Unless otherwise specified, our experiments were performed in mature junctions, which we previously defined as achieving the stationary state concerning E-cadherin levels and junctional distributions $\sim 24 \mathrm{~h}$ after the onset of cell-cell contacts (56), and were then realized 1 to 2 days after confluency (see SI). We generated stable clones overexpressing wild-type PC2 in intercellular contacts or a PC2 mutant lacking channel activity (D509V, referred to as $\mathrm{PC} 2_{\mathrm{mut}}$ ) or a truncated PC2 form. We also adopted a silencing approach through the transient transfection of PC2 shRNA. Although pathological situations in patients are mostly related to polycystin loss-of-function, we examined the effect of both over- and underexpression of PC2 to thoroughly characterize its involvement in mechanotransduction in intercellular junctions.

In wild-type (WT) cells, PC2 is present in primary cilia, the endoplasmic reticulum, and basolateral contacts of epithelial cells. In particular, it has been reported that the presence of PC2 at the intercellular contacts of MDCK cells is dependent on the state of maturation (ie. more in confluent contacts) (34), and it has been detected even before confluence (16). We found a similar pattern in 2day confluent WT cells (Fig. 1a, see also SI): endogenous PC2 was present in basal bodies (that give rise to primary cilia after 4-5 days confluence), and weakly in intercellular contacts.

We first generated stable clones after PC2 transfection and selected clones showing a strong PC2 signal at intercellular contacts. Six out of 18 clones showed clear PC2 overexpression at contacts (examples in Fig. 1b, c) but the reason for this differential localization is not known, and does not seem to be primarily dependent on expression levels (see above). It could possibly be related to the heterogeneity of the MDCK cell line, which is thought to comprise cells with different properties (6063). PC2 expression was also increased in basal bodies in stable clones, and no alteration in PC1 distribution was observed compared with WT (SI). We focused on a clone showing a strong PC2 


\section{ACCEPTED MANUSCRIPT}

overexpression at intercellular contacts, lat-PC2 (Fig. 1c). In experiments with $\alpha$-actinin (Fig. 3), we also studied another clone with clear expression at contacts, called lat-PC2-bis. Both clones overexpressed PC2 about two-fold as assessed by Western blot (Fig. 1d, e), similar to stable clones with no clear overexpression specifically at contacts (PC2-overex, Fig. 1e).

We also generated stable lines expressing a mutant form of PC2 lacking channel activity, PC2 D509V. Similar to above, clones with high expression levels at junctions were selected, and we studied two types of clones, either overexpressing only at junctions, lat-PC $2_{\text {mut }}$ (Fig. 1f), or with a similar overexpression at junctions and with a labeling of fibers near basal contacts, d-lat-PC $2_{\text {mut }}$ (data not shown). Quantification by Western blot showed that the level of expression of PC2 was increased 2-3-fold in lat-PC2 $2_{\text {mut }}$ and d-lat-PC2 $2_{\text {mut }}$ clones compared with WT (Fig. 1e). The D509V mutation is not located in a region that is involved in $\alpha$-actinin binding, which are the $\mathrm{N}$-terminal region and residues 821-878 in the C-terminal domain (16). Thus, we also studied two PC2 truncated forms that are lacking these regions: PC2-742X- $\Delta$ Nter(1-203) and PC2-813X- $\Delta$ Nter(1-203) (detailed in SI).

Lastly, we also generated shRNA against PC2. Six shRNA against PC2 were tested and the one that gave the highest reduction in immunofluorescence signal was selected and referred to as siPC2 (Fig. 1g). Scrambled (scr) siRNA was systematically tested in parallel as a control. Two other shRNAs with a progressively weaker inhibition of PC2 expression were also tested in mechanical stimulation experiments (detailed in SI). The reduction in PC2 expression was quantified by immunofluorescence (Fig. 1h), on coverslips expressing both transfected (si or scr) and nontransfected cells (Fig. 1g), which ensured equivalent PC2 labeling in both conditions. (Attempts to quantify by Western blots or RT-PCR were unsuccessful because of technical issues linked to the low number of transiently transfected cells). We observed a 50\% reduction in intercellular contacts (Fig. $1 \mathrm{~g}$, left, $\mathrm{n}=44$ ), and a 30-40\% reduction in the punctuate signal near the basal body (Fig. $1 \mathrm{~h}$, right, $\mathrm{n}=150$, significant difference for paired observations with $\mathrm{p}<10^{-3}$ ). Although PC2 silencing was only partial, si-PC2 was a useful tool in this study because (i) it had functional consequences (on the extent of intercellular calcium waves, Fig. 1e) and (ii) it clearly reversed, at least partially, overexpression 


\section{ACCEPTED MANUSCRIPT}

phenotypes (Fig. 3g, 4b). All cell lines with P2 overexpression or underexpression showed correct formation of intercellular junctions (SI).

It has been reported that cells overexpressing PC2 have a reduced proliferation rate (64-66). In agreement with these observations, the proliferation of lat-PC2 cells was also similarly reduced: after 2 days growth in complete media, the ratio of the number of lat-PC2 cells to WT cells was $0.7( \pm 0.2$, $\mathrm{n}=4)$. Conversely, si-PC2 cells grew faster than WT cells, with a ratio of si-PC2 cells to control scr cells of $1.3( \pm 0.2, n=6) 3$ days after transient transfection (SI). Also, cell lengths were found to be altered by the suppression of PC2 expression, but not significantly by PC2 overexpression. si-PC2 cells were consistently longer than WT or scr-transfected cells, as estimated from measurements of the cells' major axes. Ratios of cell lengths (si-PC2 vs WT or scr cells) systematically ranged between 1.1 and 1.25 for different phases of confluency: for example, in 2-day confluent cultures, cell lengths for si-PC2 cells vs control scr cells were respectively $19.5 \pm 0.6 \mu \mathrm{m}(\mathrm{n}=51)$ and $17.5 \pm 0.4 \mu \mathrm{m}(\mathrm{n}=56)$ (statistically significant difference). A reduction in renal cell size has been reported after PC1 overexpression (20), and our observations could partly be explained by the control of PC1 function by PC2 (67), although other mechanisms linked with PC2 channel activity might also be involved.

\section{2 - Mechanical stimulations and calcium experiments}

PC2 may be involved in mechanotransduction either through its channel activity or through its role in cytoskeleton recruitment. We first tested channel activity by studying the calcium responses of our clones upon mechanical stimulation with a glass micropipette. In these experiments, we first established contact between the cells and the pipette and we then applied a stimulation perpendicular to the junction with the pipette (Fig. 2a).

Because the simple contact with pipette may already generate a calcium influx in cells, we studied this first step before applying a perpendicular displacement. An intercellular calcium wave (ICW) was indeed generated in the case of weakly confluent cells (defined as cells that had established contacts a few hours $(<24 \mathrm{~h}$ ) before). The level of expression of PC2 correlated with the extent of this ICW (Fig. 2b-e). In WT cells, the extent of the wave was $47 \pm 5 \mu \mathrm{m}$ ( $\mathrm{n}=32$ independent fields in 6 independent 


\section{ACCEPTED MANUSCRIPT}

experiments). Given that cell lengths are typically $15-20 \mu \mathrm{m}$, the extent of ICW corresponds to 2 to 3 cells in length. In lat-PC2 cells ICW extent was $86 \pm 15 \mu \mathrm{m}(\mathrm{n}=11$ independent fields in 3 experiments), corresponding to 4-5 cells in length (Fig. 2d). In si-PC2 cells, intercellular waves were almost completely abolished under the same conditions of confluence $(29 \pm \mu \mathrm{m}, \mathrm{n}=21$ independent fields, 4 experiments). This value reflects the confinement to one unique cell in most cases (Fig. 2c). These experiments illustrate some functional consequences of the loss or gain of PC2 channel activity under different conditions; however, this behavior is not directly related to our main question of mechanotransduction in mature junctions. Although the precise characterization of the mechanisms involved is not the focus of this paper, we propose that the observed ICW may result from the release of ATP and the activation of purinergic receptors in neighboring cells (see SI).

No ICW was generated in cells confluent for at least 1 day, and in these conditions we performed experiments aimed at testing mechanotransduction in intercellular junctions. We exerted a mechanical stimulation by displacing the junction laterally $(1-3 \mu \mathrm{m})$ with a glass micropipette; such a method has previously been used to study the mechanical properties of focal contacts and adherens junctions (6870). To separate the contribution of the contact with the pipette from the desired effect of junction stimulation, experiments were performed in three stages: (i) contact with pipette near the junction; (ii) a few seconds later, the junction was perpendicularly pushed about $2 \mu \mathrm{m}$ with the glass pipette; and (iii) this new position was maintained for about $20 \mathrm{~s}$ and released (Fig. 2a).

When stimulating intercellular contacts mechanically by pushing with a pipette, there was a corresponding increase in the signal in the cell adjacent to the contacted cell (Fig. 2f). This was not blocked by concentrations up to $1 \mathrm{mM}$ gadolinium (data not shown), suggesting that mechanosensitive channels were not primarily responsible for this effect. Indeed, si-PC2 cells (Fig. $2 \mathrm{~g})$ still responded to lateral stimulation with a calcium increase that was not notably different to WT cells (Fig. 2f), and there was no significant difference in WT or overexpressing lat-PC2 cells (Fig. 2h): ratios of Fluo4 signal after/before was $1.045 \pm 0.01(n=7)$ for WT cells, $1.05 \pm 0.01(n=63)$ for 


\section{ACCEPTED MANUSCRIPT}

scr control cells, 1.04 $\pm 0.01(\mathrm{n}=16)$ for si-PC2 cells and 1.055 $\pm 0.02(\mathrm{n}=6)$ for lat-PC2 cells.

These experiments suggest that the channel activity of PC2 does not have a central role in mechanotransduction in intercellular contacts.

3 - Effect of polycystin 2 on $\alpha$-actinin reinforcement upon mechanical stimulation of intercellular junctions

Irrespective of its channel function, PC2 might be involved in the recruitment of cytoskeletal molecules upon mechanical stimulation, as previously reported for filamin (25). This is suggested by the direct interaction between these cytoskeletal molecules and PC2 (16); alternatively, these effects may be indirect, as several signaling pathways coupled to polycystins play a role in cytoskeletal regulation.

The mechanical stimulation of intercellular junctions is known to induce an accumulation of cytoskeletal proteins, in particular vinculin (13-14) and $\alpha$-actinin (4). Because polycystins bind several cytoskeletal proteins at adherens junctions such as vinculin and $\alpha$-actinin, we studied the effect of a mechanical stimulation on the recruitment of these proteins and whether this was dependent on PC2. We observed that F-actin (Fig. 3a) as well as actin cross-linking proteins vinculin (data not shown) and $\alpha$-actinin (Fig. 3b) were quickly recruited to junctions upon a lateral stimulation (and not in the first phase of pipette contact, strongly suggesting that this effect is not directly dependent on calcium entry). The extent of recruitment upon stimulation of intercellular junctions was in the same order for F-actin and $\alpha$-actinin, which was $\mathrm{I}_{\max } / \mathrm{I}_{0}=1.046 \pm 0.004(\mathrm{n}=5)$ and $1.048 \pm 0.005$ $(n=93)$ respectively.

We focused on $\alpha$-actinin because of its ability to modulate the channel activity of PC2 (16), potentially creating a retroactive loop. We observed that $\alpha$-actinin is highly dynamic in adherens junctions, even under non-stimulating conditions: from two-photon FRAP experiments, its residence time at junctions was $5 \mathrm{~s}(\mathrm{n}=5)$, which is fast compared with the residence time of other proteins from 


\section{ACCEPTED MANUSCRIPT}

the actin-cadherin system (from 30 to $240 \mathrm{~s}$ for actin-p120 and catenin-E-cadherin (71-72)), or with $\alpha$-actinin renewal in focal adhesion plaques and stress fibers, which is in the order of a minute (53). Upon mechanical stimulation of intercellular junctions, $\alpha$-actinin recruitment occurred rapidly (maximum reached before 2-3 s, Fig. 3b) and was reversed as soon as the lateral stimulation was released.

We wanted to determine whether a change in PC2 expression would lead to a change in $\alpha$-actinin recruitment upon mechanical stimulation (Fig. 3c, bottom). In the absence of mechanical stimulation, there was no statistically significant change in $\alpha$-actinin distribution and expression level (as assessed by immunofluorescence (SI) and Western blots, data not shown). When a mechanical stimulus was applied, the local recruitment of $\alpha$-actinin was partially suppressed in lat-PC2 cells (in which PC2 is overexpressed) (Fig. 3c, f) and for 60\% of these cells, there was no recruitment upon stimulation. The mean $\alpha$-actinin recruitment upon stimulation $\left(I_{\max } I_{\text {before }}\right)$ was $1.017 \pm 0.005$ for lat-PC2 cells vs $1.046 \pm 0.004$ for WT cells (significantly different, $\mathrm{p}<10^{-3}, \mathrm{n}=58$, 188; Fig. 3f, Table 1). For the independent clone lat-PC2-bis, the $\mathrm{I}_{\max } \mathrm{I}_{\text {before }}$ was $1.004 \pm 0.004$ (n=72, Fig. 3f, Table 1). This inhibition of $\alpha$-actinin mechanosensitive recruitment was not dependent on PC2 channel activity: indeed, recruitment was also inhibited in our two clones overexpressing PC2 D509V, lat-PC2 $2_{\text {mut }}(1.018 \pm 0.02)$ and d-lat-PC $2_{\text {mut }}(1.002 \pm 0.0005)(\mathrm{n}=71$ and 41 respectively, significantly different from WT with p $<10^{-3}$, Fig. 3f, Table 1). The truncation mutants PC2-742X- $\Delta$ Nter and HA-PC2-813X- $\Delta$ Nter (which lack the $\alpha$-actinin binding sites) also showed no alteration in $\alpha$-actinin recruitment $(1.046 \pm 0.006$, n=81) compared with WT (Fig. 3f, Table 1, see SI for more details). Although this may be in favor of a direct effect of PC2 binding to $\alpha$-actinin, such an extended deletion might also affect other aspects of PC2 function or trafficking.

The inhibition of $\alpha$-actinin recruitment by PC2 overexpression was clearly reversed upon PC2 silencing $\left(\mathrm{I}_{\max } \mathrm{I}_{\text {before }}\right.$ respectively of $1.043 \pm 0.005$ and $1.039 \pm 0.009$ for lat-PC2-si and lat-PC2bis-si, $\mathrm{n}=63$, 33; Fig. 3g, Table 1). After PC2 silencing in WT cells, an inhibition of recruitment was 


\section{ACCEPTED MANUSCRIPT}

observed compared with WT or control scr cells $\left(I_{\max } I_{\text {before }}\right.$ of $1.012, n=56$, which is statistically different from the scr control, $\mathrm{p}<10^{-3}$; Fig. 3g, Table 1. See also SI for other PC2 shRNA constructs).

The reason why an inhibition of recruitment is observed both with over- or underexpression of PC2 remains to be determined, and may involve either a direct interaction with $\alpha$-actinin, and/or indirect effects of signaling (possibly through a synaptopodin-actinin-vinculin complex). These experiments suggest that PC2 is involved in mechanotransduction at intercellular junctions, and more precisely that a precise balance of $\mathrm{PC} 2$ expression is required for an adequate cytoskeleton reinforcement upon mechanical stimulation of intercellular junctions.

4 - Cell movements and orientation are modulated by polycystin 2

An alteration of mechanotransduction at intercellular junctions is expected to perturb cellular responses to forces and, consequently, affect behavior on a multicellular level. Therefore, we studied the multicellular organization of our clones by investigating intercellular junction movements in confluent epithelium, and migratory properties during wound healing. PC2 might influence cell movements by its direct effect on cytoskeleton dynamic organization (eg. via $\alpha$-actinin) in response to forces, with a possible participation of its channel activity and its control of PC1 activity/ localization (33).

Intercellular junction movements in a confluent epithelium undergo small fluctuations with combined random and directed components $(71,73)$. We quantified the displacement perpendicular to the junction after a 40 min time period. In MDCK WT cells, the mean displacement was $0.38 \pm 0.015 \mu \mathrm{m}$ $(\mathrm{n}=445)(71)$. The expression of PC2 increased intercellular junction fluctuations: the displacement over 40 min was $1.68 \pm 0.17 \mu \mathrm{m}$ for lat-PC2 cells $(\mathrm{n}=90)$ (Fig. $4 \mathrm{a}$, statistically significant difference with WT, p $<0.05)$. Lat-PC $2_{\text {mut }}$ and d-lat-PC $2_{\text {mut }}$ cells showed an intermediate mobility between latPC2 and WT cells (Fig. 4a). Mean displacements over 40 min were respectively $0.51 \pm 0.16 \mu \mathrm{m}(\mathrm{n}=69)$ 


\section{ACCEPTED MANUSCRIPT}

and $0.73 \pm 0.18 \mu \mathrm{m}(\mathrm{n}=100)$ (significant difference with $\mathrm{WT}$, with $\mathrm{p}<0.05)$. Lat-PC $2_{\text {mut }}$ junctions were more mobile than WT junctions but less than lat-PC2 junctions, which may be due to the different expression and activities of clones in various subcellular compartments, in particular focal adhesions. To more directly study the influence of PC2 channel activity on junction movements, we used pharmacological inhibition of mechanosensitive channels. Neither WT nor lat-PC2 movements were altered by inhibitors of mechanosensitive channels, gadolinium $(100 \mu \mathrm{M})$ and lanthanum chloride (1 $\mathrm{mM}$ ) (mean displacement over $40 \mathrm{~min}$ were $0.31 \pm 0.01 \mu \mathrm{m}, \mathrm{n}=593\left(\mathrm{Gd}^{3+}\right)$ and $0.4 \pm 0.03 \mu \mathrm{m}, \mathrm{n}=93$ $\left(\mathrm{La}^{3+}\right)$ for WT cells, and $1.68 \pm 0.15 \mu \mathrm{m}, \mathrm{n}=40\left(\mathrm{Gd}^{3+}\right)$, and $1.65 \pm 0.17 \mu \mathrm{m}, \mathrm{n}=30\left(\mathrm{La}^{3+}\right)$ for lat-PC2 cells).

Silencing of PC2 by siRNA led to a decrease of about one third in the extent of intercellular junction movements: mean displacement in 100 min was $2.12 \pm 0.12 \mu \mathrm{m}$ for si-PC2 cells $(\mathrm{n}=204)$ vs $3 \pm 0.16 \mu \mathrm{m}$ for control scr cells $(\mathrm{n}=189)$ (statistically significant difference with $\mathrm{p}<0.05)$ (Fig. $4 \mathrm{~b}$ ) (note that the basal displacement was higher in experiments with siRNA (Fig. 4b compared with Fig. 4a) because for technical reasons linked to transfection, cells were visualized only one day after seeding, in which case movements are stronger). siRNA also partly rescued the increase in movements generated by PC2 lateral overexpression: mean displacement in $40 \mathrm{~min}, 2.12 \pm 0.21 \mu \mathrm{m}$ for lat-PC2 transfected with PC2 siRNA cells $(\mathrm{n}=60)$ vs $3.65 \pm 0.26 \mu \mathrm{m}$ for lat-PC2 transfected with control scr plasmid $(\mathrm{n}=70)$ (statistically significant difference with $\mathrm{p}<0.05)$. This corresponds to a reversion of about $50 \%$ of the increase of movements due to PC2 overexpression. Therefore, the expression of PC2 at contacts increases mobility in confluent cells whereas silencing decreases it, and these effects are at least partially independent of PC2 channel activity (Fig. 4a, b).

We studied whether PC2 was also involved in the organization of subconfluent cultures or during wound healing. We initially observed that subconfluent lat-PC2 or d-lat-PC $2_{\text {mut }}$ cells showed a smooth organization of cell contours, which is in contrast to the scattered morphology reported in cells expressing PC1 (33). We addressed the question of polarization in a system of controlled wound 


\section{ACCEPTED MANUSCRIPT}

healing, in which MDCK cells exhibit polarized structures named migration fingers (74). The analysis was performed through manual counting of migration fingers and automated Particle Image Velocimetry (PIV) analysis by AVeMap software (55). Fig. 4c-f shows typical velocity fields obtained during wound healing by PIV, with a migration finger beginning to form in WT (Fig. 4c) and d-lat-PC $2_{\text {mut }}$ monolayers (Fig. $4 \mathrm{e}$ ) that have a velocity field oriented perpendicular to the wound. Polarized migration fingers were not seen in lat-PC2 cells, and their number was reduced in si-PC2 cells (Fig. 4g). This is linked to a loss of orientation in lat-PC2 and si-PC2 cells (Fig. 4h): orientation was estimated from the order parameter, $\langle\cos \theta>$, where $\theta$ is the angle between the velocity vector in a given area and the direction perpendicular to the wound (the order parameter is equal to 1 for a movement perfectly oriented, and to 0 for a movement with random orientation). Mean order parameters were 0.57 (WT), 0.33 (lat-PC2), 0.54 (lat-PC2 $2_{\text {mut }}$ ), 0.55 (d-lat-PC2 $2_{\text {mut }}$ ), 0.6 (scr) and 0.47 (si-PC2) (Fig. 4h).

This loss of finger formation and orientation are in line with the loss of tubulogenesis (branched morphogenesis) in 3D experiments in cells overexpressing PC2 (64), and a loss of orientation in PC2-depleted endothelial cells (75). In addition, PIV analysis revealed a slower migration rate for lat-PC2 cells, d-lat-PC2 ${ }_{\text {mut }}$ cells and si-PC2 cells (17.3 (WT), 6.7 (lat-PC2), 20 (lat$\left.\mathrm{PC} 2_{\mathrm{mut}}\right), 11$ (d-lat-PC $\left.2_{\mathrm{mut}}\right), 17.2(\mathrm{scr})$ and $\left.12.3(\mathrm{si}-\mathrm{PC} 2) \mu \mathrm{m} / \mathrm{h}\right)$. These experiments indicate that PC2 is involved in migration during wound healing and in the formation of polarized structures as a result of its channel activity (as there was no alteration of orientation in PC2 D509V clones), and similar effects of loss of orientation and reduced velocity were seen in cells over- or underexpressing PC2.

The two different integrated phenotypes reported here (dynamics in a confluent epithelium and wound healing) each result from a complex combination of mechanisms, probably comprising but not restricted to dynamic actin organization of intercellular junctions. Note that for cells deficient in PC1, defects in wound healing involved both the actin and the microtubule cytoskeleton, with a crucial involvement of focal adhesion dynamics (76). In agreement with this complexity, phenotypes observed at a multicellular level do not simultaneously mirror both characteristics of $\alpha$-actinin recruitment at junctions - that is, independence from channel activity and a similar effect for PC2 


\section{ACCEPTED MANUSCRIPT}

under- and overexpression. However, because the organization and kinetics of $\alpha$-actinin strongly modulate the mechanical properties of cells (47), mechanotransduction at intercellular contacts by PC2 should be integrated into future models of epithelium dynamics and fluctuations in ADPKD. 


\section{ACCEPTED MANUSCRIPT}

\section{Discussion}

We report here that PC2 is involved in the control of spontaneous cell movements and orientation, and in cytoskeleton ( $\alpha$-actinin) recruitment following mechanical stimulation. Our data strongly suggest that PC2 has a role in mechanotransduction in intercellular contacts. ADPKD is classically seen as a ciliopathy, with alterations in normal PC2 channel activity upon mechanical stimulation; however, recent studies do not support the notion that there is a calcium-responsive activity in primary cilia (24). Nevertheless, polycystins are likely to have a role in primary cilia mechanosensing as signaling complexes, but our study highlights the importance of considering their mechanosensitive activity in other subcellular structures. In intercellular contacts, we found that mechanotransduction by PC2 mainly acted through cytoskeleton recruitment, and not (or only marginally) through its cation channel function. This situation is reminiscent of the mechanism described in vascular smooth muscle cells, where the dosage of $\mathrm{PC} 1$ and $\mathrm{PC} 2$ determines pressure sensing through filamin A recruitment by PC2 and not by PC2 channel function (25).

Our data leave open three main questions:

(1) Why is the same effect observed for over- and underexpression of PC2? Is this physiologically relevant?

(2) What can then be the mechanism of $\alpha$-actinin recruitment - is it a direct or an indirect effect?

(3) Is the observed effect only mediated by intercellular contacts?

(1) It is striking that we observed the same effect for over- and underexpression of PC2. ADPKD results from mutations that lead to the loss-of-function of polycystins. However, in animal models, not only polycystin loss-of-function but also gain-of-function can generate kidney cysts evocative of ADPKD. Overexpression of PKD2 (coding for PC2) in mice led to cyst formation and development from a range of renal tubule segments - evoking the clinical features of human ADPKD - with associated upregulation of B-Raf/MEK/ERK signaling and downregulation of phosphorylated Akt 


\section{ACCEPTED MANUSCRIPT}

(77). In another mouse model, overexpression of PKD2 was associated with progressive disorganization of the renal cortex, abnormal tubular organization and the apparition of a few microcysts (78). Similarly, several mouse models overexpressing PKD1 also led to cyst formation and to extrarenal manifestations observed in ADPKD (79-80). This is in line with the fact that a precise dosage of polycystins is necessary for their adequate function, with possibly similar functional effects upon over- or underexpression.

(2) However, mechanistically, can a direct involvement of PC2 in $\alpha$-actinin recruitment be reconciled with the fact that over- and underexpression have the same effect? PC2 can directly bind to $\alpha$-actinin, and although deleting the $\alpha$-actinin-binding site leads to a loss of $\alpha$-actinin inhibition of recruitment in our experiments, the PC2 interaction domain is large (involving both $\mathrm{N}$ - and a part of C-terminal domain) and deleting it may have other, non-specific effects. $\alpha$-actinin targeting to junctions depends on its central spectrin repeats-rich domain, which binds to PC2 (as well as to vinculin and $\alpha$-catenin); synaptopodin is also needed for this recruitment (4). We find it unlikely that in a very simple model (in which PC2 would recruit $\alpha$-actinin without the intervention of a more interlaced complex and/or signaling pathways), overexpression would have the same effect as underexpression. Our data may be compatible with either of the two following models (or a combination of both):

- Model 1: modulation of $\alpha$-actinin (-vinculin- $\alpha$-catenin-synaptopodin---zyxin?) complex by direct interactions with polycystins.

Complex interactions, involving reciprocal/sequential unmasking of cryptic sites, occur during the stretching of $\alpha$-catenin, $\alpha$-actinin and vinculin recruitment upon mechanical stress (4). This leads to the recruitment of additional actin-binding proteins and to a final rigidification with cooperative effects on cytoskeleton stiffness (81). Vinculin and $\alpha$-actinin both bind polycystins (1 or 2). Because of these complex unmasking sequences, it could be envisioned that a certain amount of PC2 binding to $\alpha$-actinin might facilitate the recruitment of the latter (eg by unmasking and integration in the complex), but that too large an amount may prevent appropriate binding of other intermediates in the complex. 


\section{ACCEPTED MANUSCRIPT}

- Model 2: modulation of $\alpha$-actinin complex by signaling by polycystins.

Polycystins are involved in many signaling pathways, and their presence in the synaptopodin complex might alter its signaling in a number of ways, with probably an adequate dosage necessary for the required effect. This model would be easier to reconcile with the similar effect observed for underand overexpression. As examples, Akt phosphorylation elicited by mechanical stimulation depends on synaptopodin (4), polycystins are known to modulate the PI3K/Akt pathway (82), and ERK, which binds $\alpha$-actinin and actin, is improperly activated in ADPKD models $(20,77)$.

The interaction between PC1 and PC2 is likely to be central in both models because PC1 is involved in a number of signaling pathways and links several actin-binding proteins, including vinculin. However, studying the involvement of $\mathrm{PC} 1$ or of the whole PC1/PC2 complex in cytoskeleton recruitment upon mechanical stimulation was beyond the scope of this study.

(3) Is the observed effect of PC2 restricted to the particular organization of adherens junctions? In our experiments, PC2 was not only strongly overexpressed in intercellular contacts, but also in other sites (basal bodies and possibly - from localizations described in the literature - endoplasmic reticulum or focal contacts) - although not in primary cilia, which had not yet appeared. Similarly, PC2 inhibition by shRNA was not restricted to intercellular junctions. Thus, we can not strictly exclude that we observed a more general phenomenon that would also be effective in other sites (basal bodies), or in other adhesions by mechanisms described in focal contacts (83-84) (including vinculin-actinin interactions), or by mechanisms involving direct sensing by F-actin fibers (58) or repair involving zyxin recruitment $(45-46,85)$. However, these mechanisms do not include primary cilia, and are highly likely to be related to actin organization at junctions.

On a multicellular scale, we report complex effects of PC2 on movement and orientation, with some of them reminiscent of findings in the literature $(33,64,75,86)$, and we provide a novel description of orientation after wound healing. Because mechanotransduction at junctions is involved in the adjustment of intercellular forces, it is expected to play a role in these dynamic behaviors; in particular, alterations of movements in confluent epithelia seem to be largely independent of channel 


\section{ACCEPTED MANUSCRIPT}

function, similar to cytoskeleton recruitment at junctions. Other causes, linked to channel activity, signaling pathways and interactions with $\mathrm{PC} 1$, will of course be integrated in these phenomena, in particular for cell orientation (76). However, our study illustrates the necessity of taking mechanotransduction into account in adhesive contacts when studying tissular disorganization in polycystic kidney diseases.

Finally, concerning the molecular players of mechanotransduction in intercellular contacts, it will be important to study the influence of $\mathrm{PC} 1$ and of the $\mathrm{PC} 1 / \mathrm{PC} 2$ ratio on intercellular mechanotransduction, which goes beyond the scope of this paper. PC1 could represent a primary mechanosensor in adherens junctions; indeed, it establishes homophilic interactions between cells (87), and its large transmembrane part has unfolding properties that would be in agreement with such a role; deletions in the PC1 extracellular domain are found in many ADPKD mutations. In addition, it will be interesting to study the contribution of other putative mechanosensitive ion channels to intercellular mechanotransduction. Other TRP channels are expressed in intercellular contacts, in particular TRPM7, which is responsible for calcium flicker activity upon mechanical stimulation of focal contacts (88), TRPC4 in the vascular endothelium, where cell-cell contact formation governs $\mathrm{Ca}^{2+}$ signaling by this channel (89), or TRPV4. The participation of these channels in intercellular mechanotransduction, and their interplay with PC2, will need to be evaluated.

In conclusion, our data strongly suggest that tissular disorders observed in ADPKD should be interpreted not only in terms of ciliopathies, but also in terms of the perturbation of mechanotransduction and cytoskeleton modulation in intercellular or adhesive contacts.

\section{Acknowledgements}

We are very grateful to Jean Octon and Fatima Bajjou for their experimental contribution to this paper. We thank Pascal Silberzan, Isabelle Bonnet, Olivier Cochet, Simon Garcia, and Maxime Deforet for their help with wound-healing experiments, AVeMap and image analysis. We wish to thank Eric Honoré, Amanda Patel and Fabrice Duprat for insightful discussions about polycystins and 


\section{ACCEPTED MANUSCRIPT}

suggestions, and for providing us with important biological material. We are grateful to Sophie Saunier for important discussions and for reading the manuscript. We thank Monique Arpin and Laurence Del Maestro for sharing modified pSIRNA plasmid, Carol Otey for sharing $\alpha$-actinin plasmid, WJ Nelson for sharing E-cadherin-GFP MDCK cell line, and Bela Papp for discussions about biochemical aspects. We greatly acknowledge Fanny Cayrac and Anne-Christine Brunet for cell biology, Lucie Sengmanivong of the Nikon Imaging Centre @ Institut Curie-CNRS, François Waharte and Vincent Fraisier from the PICT-IBiSA Lhomond Imaging facility of Institut Curie, and the cytometry facility of Institut Curie. We thank Susan Simpson for careful reading of the text. This work was sponsored by the CNRS (Centre National de la Recherche Scientifique) and Institut Curie. 


\section{Legends to the figures}

Figure 1: Over- or underexpression of polycystin 2 in junctions of MDCK cells, Schemes recapitulating transfection and selection of clones are indicated. (a) PC2 immunofluorescence on WT MDCK cells, (b) on a stable clone mildly overexpressing PC2 at intercellular contacts (green), with $\gamma$ tubulin co-labeling (red) (all PC2 in "basal bodies" was colocalized with $\gamma$-tubulin, yellow), (c) on latPC2 clone strongly overexpressing PC2 in intercellular contacts (confocal imaging). (d, e) Western blot experiments with anti-PC2 antibody. Intensity of bands (e, top) was normalized with Ponceau red staining indicating total protein amount (e, bottom). (f) PC2 immunofluorescence (green, with $\gamma$ tubulin labeling in red) of lat-PC $2_{\text {mut }}$ clone overexpressing PC2-D509V in intercellular contacts. $(\mathrm{g})$ PC2 siRNA cells (si-PC2): (left) transiently transfected cells are identified by their cytosolic mCherry fluorescence. (middle) corresponding PC2 immunofluorescence: transiently transfected red cells exhibit a lower PC2 labeling in indicated areas. (right) merge. (h) Quantification of immunofluorescence signals for cells inside (si-PC2 or scr)/outside (ctr) the transfected areas in the same coverslips. Left, measurements on intercellular junctions; right, on basal bodies. Scale bars represent $10 \mu \mathrm{m}$. Cells were confluent for $\sim 2$ days for all conditions.

Figure 2: Effect of mechanical stimulations on cell calcium concentration, (a) Principle of the experiments reported in Figs. 2 and 3. A microforged glass micropipette was put near a junction of a fluorescent cell, a pause of several seconds was done to distinguish effects due to pipette contact from effects due to mechanical stimulation of the junction. Next, the junction was displaced perpendicularly by 1-4 $\mu \mathrm{m}$ (statistics correspond to "push" actions) and maintained about $20 \mathrm{~s}$, and then the contact with the micropipette was released, leading to the return of the junction close to its position before stimulation and the return of fluorescence to its baseline level. (b, c, d) Intercellular calcium wave (Fluo4 labeling) after simple contact pipette, respectively for WT, si-PC2 and lat-PC2 cells. The cell contacted corresponds to the first white circle, the following circles allow the extent of the intercellular calcium wave (ICW) to be visualized; the four images for each condition correspond to times before contact, immediately after contact, $1 \mathrm{~s}$ after contact, and at the maximal extension of the ICW (4 s). (e) Width of ICW after pipette contact, for si-PC2, WT and lat-PC2 cells. (f, g) Lateral displacements of junctions, for WT and si-PC2 cells, immediately before and at the maximal signal in adjacent cells (typically 2-3 s), with lateral displacements of 1.5 and $2 \mu \mathrm{m}$ respectively (h) Increase in Fluo4 fluorescence after mechanical stimulation of the junction. $\mathrm{I}_{\max } / \mathrm{I}_{\text {before }}$ is reported, where $\mathrm{I}_{\text {before }}$ is the mean Fluo4 signal in a small region at the stimulated junction immediately before stimulation, and $\mathrm{I}_{\max }$ at the time of maximal stimulation (typically $1 \mathrm{~s}$ ). Scale bars represent $10 \mu \mathrm{m}$.

Figure 3: $\alpha$-actinin recruitment upon mechanical stimulation of intercellular junctions, Mechanical stimulations of intercellular junctions for (a) MDCK LifeAct-GFP cells and (b) MDCK cells transfected with $\alpha$-actinin-EGFP. Arrows indicate contact with the micropipette. Images before stimulation, immediately after pipette contact (before lateral displacement), and $2 \mathrm{~s}$ after a junction displacement of about $2 \mu \mathrm{m}$. Scale bars represent $10 \mu \mathrm{m}$. (c) Mechanical stimulation on MDCK latPC2 cells transfected with $\alpha$-actinin-EGFP and (d) si-PC2 cells co-transfected with $\alpha$-actinin-EGFP, image of junction immediately before and $1 \mathrm{~s}$ after junction displacement. (e) Characteristic curves of temporal evolution of local fluorescence signal for WT, si-PC2 and lat-PC2 cells. The decay of curves corresponds to observational photobleaching. Arrows indicate stimulation (junction displacement) and release events. (f, g) Recruitment of $\alpha$-actinin-EGFP fluorescence after mechanical stimulation of the junction. $I_{\max } / I_{0}$ is reported, where $I_{0}$ is the mean signal in a small region at the stimulated junction immediately before stimulation, and $I_{\max }$ at the time of maximal stimulation (typically 1-3 s), or if no stimulation occurs, $1 \mathrm{~s}$ after stimulation. Horizontal bars correspond to mean values: see Table 1 for statistics. (f) PC2 overexpression. Individual values obtained for: WT (black; WT scr: grey), lat-PC2 (red; lat-PC2-scr: orange), lat-PC2-bis (orange; lat-PC2bis-scr, yellow), lat-PC $2_{\text {mut }}$ (green), d-lat$\mathrm{PC} 2{ }_{\text {mut }}$ (light green), truncated PC2 forms: PC2-742X $\Delta \mathrm{N}$ (blue, transient transfection) / PC2-813X $\Delta \mathrm{N}$ (rose, transient transfection, magenta, stable pool, violet, stable clones). (g) Reversion and PC2 silencing. Individual values obtained for: lat-PC2 (red; lat-PC2-scr: orange), lat-PC2 si-PC2 (violet), 


\section{ACCEPTED MANUSCRIPT}

lat-PC2-bis (orange; lat-PC2-bis-scr, yellow), lat-PC2-bis si-PC2 (magenta), WT (black; WT scr, grey) and si-PC2 (blue). * indicates statistically significant differences with $\mathrm{p}<10^{-3}$, see Table 1.

Figure 4: Multicellular dynamics in polycystin 2-modified cells, (a) Quantification of intercellular junction movements in cells confluent for 2 days, for WT MDCK cells, WT treated with $\mathrm{Gd}^{3+}$ or $\mathrm{La}^{3+}$, lat-PC2 (1-PC2) cells, lat-PC2 cells with $\mathrm{Gd}^{3+}$ or $\mathrm{La}^{3+}$, and for cell lines expressing PC2-D509V (1PC2 mut and d-1-PC2 mut) without channel activity. Perpendicular junction movement in 40 min was measured. *: statistically significant difference with WT. (b) Junction displacement in siRNA cells and controls, one day after flow cytometry sorting and plating at confluency. Right, mean perpendicular displacement in $100 \mathrm{~min}$ in scr vs si-PC2 cells; left, mean displacement in $40 \mathrm{~min}$ in latPC2 siRNA vs lat-PC2 scr cells. *: statistically significant difference in pairs of observations. (c-f) Wound healing assays for the formation of polarized migration fingers, respectively for WT, lat-PC2, $\mathrm{d}$-lat-PC $2_{\text {mut }}$ and si-PC2 cells, $4 \mathrm{~h}$ after stencil removal. A nascent migration finger is visible in (c). Green arrows correspond to velocity fields obtained by PIV analysis between two successive frames (here normalized within each frame for graphical representation). Scale bars represent $100 \mu \mathrm{m}$. (g-i) Analysis of wound-healing experiments: WT, black, lat-PC2, red, lat-PC $2_{\text {mut }}$, green and d-lat-PC2 $2_{\text {mut }}$, dark green, scr, brown, si-PC2, blue. (g) Number of migration fingers by frame (manual counting of fingers that persist till the end of observation $(16 \mathrm{~h})$ after formation). (h) Order parameter $(<\cos \theta>)$ for individual wound-healing experiments, mean over the whole observation time, (i) Velocity as a function of time (mean of 6-12 acquisitions per condition during the 4 first hours of wound healing); PIV analysis on a band of $80 \mu \mathrm{m}$ along the wound. * indicates a significantly statistical difference.

Table 1: Statistics on $\alpha$-actinin recruitment, For each condition, mean, standard error of the mean and the number of measurements are indicated. Statistically significant differences with $p<10^{-3}$ are indicated in the column "different from". All comparisons between scr and si-PC2 (for WT, lat-C2 or lat-PC2-bis cell lines) refer to experiments with parallel transfection and measurements for these two conditions. Transfection with control scrambled RNA (scr) is expected to have no influence on behavior, justifying the fact that this condition is pooled with the non-transfected condition in $(\mathrm{c}, \mathrm{f}, \mathrm{i})$ columns (bold).

\begin{tabular}{|c|c|c|c|c|c|}
\hline & & & S.E.M. & $\mathrm{n}$ & different from \\
\hline$a$ & WT & 1.046 & 0.004 & 134 & $\mathrm{~d}, \mathrm{~g}, \mathrm{j}, \mathrm{k}$ \\
\hline b & WT scr & 1.047 & 0.008 & 54 & I, o \\
\hline c & & & & & \\
\hline$(=\{a, b\})$ & WT with WT scr & 1.046 & 0.004 & 188 & $\mathrm{f}, \mathrm{i}, \mathrm{I}$ \\
\hline d & lat-PC2 & 1.018 & 0.009 & 28 & a \\
\hline $\begin{array}{l}e \\
f\end{array}$ & lat-PC2 scr & 1.017 & 0.005 & 29 & $\mathrm{~m}$ \\
\hline$(=\{d, e\})$ & lat-PC2 with lat-PC2 scr & 1.017 & 0.005 & 58 & a \\
\hline g & lat-PC2-bis & 1.009 & 0.004 & 58 & a \\
\hline h & lat-PC2-bis scr & 1.002 & 0.005 & 14 & $\mathrm{n}$ \\
\hline$(=\{g, h\})$ & lat-PC2-bis with lat-PC2-bis scr & 1.007 & 0.004 & 72 & C \\
\hline j & lat-PC2mut & 1.018 & 0.02 & 71 & a \\
\hline k & d-lat-PC2mut & 1.002 & 0.005 & 41 & a \\
\hline । & WT si & 1.012 & 0.006 & 56 & $b, c, m$ \\
\hline $\mathrm{m}$ & lat-PC2 si & 1.043 & 0.005 & 63 & $e, I$ \\
\hline $\mathrm{n}$ & lat-PC2-bis si & 1.039 & 0.009 & 33 & $\mathrm{~h}$ \\
\hline 0 & PC2-interm-si & 1.01 & 0.005 & 36 & $b, p$ \\
\hline $\mathrm{p}$ & PC2-low-si & 1.053 & 0.009 & 33 & 0 \\
\hline$q$ & PC2-trans & 1.002 & 0.008 & 22 & r \\
\hline$r$ & $\Delta \mathrm{N}-\Delta \mathrm{C} 813 \mathrm{X}$ & 1.046 & 0.007 & 81 & $q$ \\
\hline
\end{tabular}


References

1. Gumbiner BM (2005) Regulation of cadherin-mediated adhesion in morphogenesis. Nat Rev Mol Cell Biol 6(8):622-634.

2. Drees F, Pokutta S, Yamada S, Nelson WJ, \& Weis WI (2005) Alpha-catenin is a molecular switch that binds E-cadherin-beta-catenin and regulates actin-filament assembly. Cell 123(5):903-915.

3. Smutny M, et al. (2010) Myosin II isoforms identify distinct functional modules that support integrity of the epithelial zonula adherens. Nat Cell Biol 12(7):696-702

4. Kannan N \& Tang VW (2015) Synaptopodin couples epithelial contractility to alphaactinin-4-dependent junction maturation. J Cell Biol 211(2):407-434

5. Huveneers S \& de Rooij J (2013) Mechanosensitive systems at the cadherin-F-actin interface. J Cell Sci 126(Pt 2):403-413

6. Pedersen SF, Owsianik G, \& Nilius B (2005) TRP channels: an overview. Cell Calcium 38(3-4):233-252.

7. Kuipers AJ, Middelbeek J, \& van Leeuwen FN (2012) Mechanoregulation of cytoskeletal dynamics by TRP channels. Eur J Cell Biol 91(11-12):834-846

8. Thodeti CK, et al. (2009) TRPV4 channels mediate cyclic strain-induced endothelial cell reorientation through integrin-to-integrin signaling. Circ Res 104(9):1123-1130.

9. Huan Y \& van Adelsberg J (1999) Polycystin-1, the PKD1 gene product, is in a complex containing E-cadherin and the catenins. J Clin Invest 104(10):1459-1468.

10. Giamarchi A, Padilla F, Crest M, Honore E, \& Delmas P (2006) TRPP2: Ca2+permeable cation channel and more. Cell Mol Biol (Noisy-le-grand) 52(8):105-114.

11. Wilson PD (2001) Polycystin: new aspects of structure, function, and regulation. J Am Soc Nephrol 12(4):834-845

12. Wilson PD, Geng L, Li X, \& Burrow CR (1999) The PKD1 gene product, "polycystin-1," is a tyrosine-phosphorylated protein that colocalizes with alpha2beta1-integrin in focal clusters in adherent renal epithelia. Lab Invest 79(10):1311-1323

13. le Duc Q, et al. (2010) Vinculin potentiates E-cadherin mechanosensing and is recruited to actin-anchored sites within adherens junctions in a myosin II-dependent manner. J Cell Biol 189(7):1107-1115.

14. Yonemura S, Wada Y, Watanabe T, Nagafuchi A, \& Shibata M (2010) alpha-Catenin as a tension transducer that induces adherens junction development. Nat Cell Biol 12(6):533-542.

15. Rundle DR, Gorbsky G, \& Tsiokas L (2004) PKD2 interacts and co-localizes with mDia1 to mitotic spindles of dividing cells: role of mDia1 IN PKD2 localization to mitotic spindles. J Biol Chem 279(28):29728-29739

16. Li Q, et al. (2005) Alpha-actinin associates with polycystin-2 and regulates its channel activity. Hum Mol Genet 14(12):1587-1603.

17. Weimbs T (2006) Regulation of mTOR by polycystin-1: is polycystic kidney disease a case of futile repair? Cell Cycle 5(21):2425-2429.

18. Fischer E, et al. (2006) Defective planar cell polarity in polycystic kidney disease. Nat Genet 38(1):21-23.

19. Boletta A, et al. (2000) Polycystin-1, the gene product of PKD1, induces resistance to apoptosis and spontaneous tubulogenesis in MDCK cells. Mol Cell 6(5):1267-1273.

20. Distefano G, et al. (2009) Polycystin-1 regulates extracellular signal-regulated kinasedependent phosphorylation of tuberin to control cell size through mTOR and its downstream effectors S6K and 4EBP1. Mol Cell Biol 29(9):2359-2371.

21. Kuo IY, et al. (2014) Cyst formation following disruption of intracellular calcium signaling. Proc Natl Acad Sci U S A 111(39):14283-14288 


\section{ACCEPTED MANUSCRIPT}

22. Retailleau K \& Duprat F (2014) Polycystins and partners: proposed role in mechanosensitivity. J Physiol 592(Pt 12):2453-2471

23. Nauli SM, et al. (2003) Polycystins 1 and 2 mediate mechanosensation in the primary cilium of kidney cells. Nat Genet 33(2):129-137.

24. Delling M, et al. (2016) Primary cilia are not calcium-responsive mechanosensors. Nature 531(7596):656-660

25. Sharif-Naeini R, et al. (2009) Polycystin-1 and -2 dosage regulates pressure sensing. Cell 139(3):587-596.

26. Xiao ZS \& Quarles LD (Role of the polycytin-primary cilia complex in bone development and mechanosensing. Ann N Y Acad Sci 1192:410-421.

27. Wang H, et al. (2014) Polycystin-1 mediates mechanical strain-induced osteoblastic mechanoresponses via potentiation of intracellular calcium and Akt/beta-catenin pathway. PLoS One 9(3):e91730

28. $\mathrm{Xu} \mathrm{H}$, et al. (2014) Polycystin 2 is involved in the nitric oxide production in responding to oscillating fluid shear in MLO-Y4 cells. J Biomech 47(2):387-391

29. Weimbs $\mathrm{T}$ (2007) Polycystic kidney disease and renal injury repair: common pathways, fluid flow, and the function of polycystin-1. Am J Physiol Renal Physiol 293(5):F1423-1432.

30. Charron AJ, Nakamura S, Bacallao R, \& Wandinger-Ness A (2000) Compromised cytoarchitecture and polarized trafficking in autosomal dominant polycystic kidney disease cells. J Cell Biol 149(1):111-124.

31. Xu JX, et al. (2014) Polycystin-1 and Galpha12 regulate the cleavage of E-cadherin in kidney epithelial cells. Physiol Genomics:physiolgenomics 0009002014

32. Markoff A, et al. (2007) Annexin A5 interacts with polycystin-1 and interferes with the polycystin-1 stimulated recruitment of E-cadherin into adherens junctions. J Mol Biol 369(4):954-966.

33. Boca $M$, et al. (2007) Polycystin-1 induces cell migration by regulating phosphatidylinositol 3-kinase-dependent cytoskeletal rearrangements and GSK3betadependent cell cell mechanical adhesion. Mol Biol Cell 18(10):4050-4061.

34. Scheffers MS, et al. (2004) Altered distribution and co-localization of polycystin-2 with polycystin-1 in MDCK cells after wounding stress. Exp Cell Res 292(1):219230.

35. Hijikata T, et al. (1997) Unanticipated temporal and spatial effects of sarcomeric alpha-actinin peptides expressed in PtK2 cells. Cell Motil Cytoskeleton 38(1):54-74

36. Witke W, Hofmann A, Koppel B, Schleicher M, \& Noegel AA (1993) The Ca(2+)binding domains in non-muscle type alpha-actinin: biochemical and genetic analysis. J Cell Biol 121(3):599-606

37. Reinhard M, et al. (1999) An alpha-actinin binding site of zyxin is essential for subcellular zyxin localization and alpha-actinin recruitment. J Biol Chem 274(19):13410-13418

38. Maruoka ND, et al. (2000) alpha-actinin-2 couples to cardiac Kv1.5 channels, regulating current density and channel localization in HEK cells. FEBS Lett 473(2):188-194

39. Corgan AM, Singleton C, Santoso CB, \& Greenwood JA (2004) Phosphoinositides differentially regulate alpha-actinin flexibility and function. Biochem $\mathrm{J} 378(\mathrm{Pt}$ 3):1067-1072

40. Li B \& Trueb B (2001) Analysis of the alpha-actinin/zyxin interaction. J Biol Chem 276(36):33328-33335 


\section{ACCEPTED MANUSCRIPT}

41. Otey CA, Vasquez GB, Burridge K, \& Erickson BW (1993) Mapping of the alphaactinin binding site within the beta 1 integrin cytoplasmic domain. J Biol Chem 268(28):21193-21197

42. Nieset JE, et al. (1997) Characterization of the interactions of alpha-catenin with alpha-actinin and beta-catenin/plakoglobin. J Cell Sci 110 ( Pt 8):1013-1022

43. Wyszynski M, et al. (1997) Competitive binding of alpha-actinin and calmodulin to the NMDA receptor. Nature 385(6615):439-442

44. Cantero Mdel R \& Cantiello HF (2015) Polycystin-2 (TRPP2) Regulation by Ca(2+) Is Effected and Diversified by Actin-Binding Proteins. Biophys J 108(9):2191-2200

45. Hoffman LM, Jensen CC, Chaturvedi A, Yoshigi M, \& Beckerle MC (2012) Stretchinduced actin remodeling requires targeting of zyxin to stress fibers and recruitment of actin regulators. Mol Biol Cell 23(10):1846-1859

46. Smith MA, et al. (2010) A zyxin-mediated mechanism for actin stress fiber maintenance and repair. Dev Cell 19(3):365-376

47. Ehrlicher AJ, et al. (2015) Alpha-actinin binding kinetics modulate cellular dynamics and force generation. Proc Natl Acad Sci U S A

48. Gluck U \& Ben-Ze'ev A (1994) Modulation of alpha-actinin levels affects cell motility and confers tumorigenicity on 3T3 cells. J Cell Sci 107 ( Pt 7):1773-1782.

49. Honda K, et al. (2005) Actinin-4 increases cell motility and promotes lymph node metastasis of colorectal cancer. Gastroenterology 128(1):51-62

50. Koizumi T, et al. (2010) The role of actinin-4 in bladder cancer invasion. Urology 75(2):357-364

51. Barbolina MV, et al. (2008) Motility-related actinin alpha-4 is associated with advanced and metastatic ovarian carcinoma. Lab Invest 88(6):602-614

52. Shao H, Li S, Watkins SC, \& Wells A (2014) alpha-Actinin-4 Is Required for Amoeboid-type Invasiveness of Melanoma Cells. J Biol Chem 289(47):32717-32728

53. Edlund M, Lotano MA, \& Otey CA (2001) Dynamics of alpha-actinin in focal adhesions and stress fibers visualized with alpha-actinin-green fluorescent protein. Cell Motil Cytoskeleton 48(3):190-200.

54. Poujade M, et al. (2007) Collective migration of an epithelial monolayer in response to a model wound. Proc Natl Acad Sci U S A 104(41):15988-15993

55. Deforet M, et al. (2012) Automated velocity mapping of migrating cell populations (AVeMap). Nat Methods 9(11):1081-1083

56. de Beco S, Gueudry C, Amblard F, \& Coscoy S (2009) Endocytosis is required for Ecadherin redistribution at mature adherens junctions. Proc Natl Acad Sci U S A 106(17):7010-7015.

57. de Beco S, Perney JB, Coscoy S, \& Amblard F (2015) Mechanosensitive Adaptation of E-Cadherin Turnover across adherens Junctions. PLoS One 10(6):e0128281

58. Hirata H, et al. (2014) Actomyosin bundles serve as a tension sensor and a platform for ERK activation. EMBO Rep

59. Kervrann C \& Boulanger J (2006) Optimal spatial adaptation for patch-based image denoising. IEEE Trans Image Process 15(10):2866-2878

60. Lugovtsev VY, Melnyk D, \& Weir JP (2013) Heterogeneity of the MDCK cell line and its applicability for influenza virus research. PLoS One 8(9):e75014

61. Omeir RL, et al. (2011) Heterogeneity of the tumorigenic phenotype expressed by Madin-Darby canine kidney cells. Comp Med 61(3):243-250

62. Arthur JM (2000) The MDCK cell line is made up of populations of cells with diverse resistive and transport properties. Tissue Cell 32(5):446-450

63. Gerceker AA, Zaidi T, Marks P, Golan DE, \& Pier GB (2000) Impact of heterogeneity within cultured cells on bacterial invasion: analysis of Pseudomonas 


\section{ACCEPTED MANUSCRIPT}

aeruginosa and Salmonella enterica serovar typhi entry into MDCK cells by using a green fluorescent protein-labelled cystic fibrosis transmembrane conductance regulator receptor. Infect Immun 68(2):861-870

64. Grimm DH, et al. (2006) Polycystin-2 regulates proliferation and branching morphogenesis in kidney epithelial cells. J Biol Chem 281(1):137-144.

65. Bhunia AK, et al. (2002) PKD1 induces p21(waf1) and regulation of the cell cycle via direct activation of the JAK-STAT signaling pathway in a process requiring PKD2. Cell 109(2):157-168.

66. Li X, et al. (2005) Polycystin-1 and polycystin-2 regulate the cell cycle through the helix-loop-helix inhibitor Id2. Nat Cell Biol 7(12):1202-1212.

67. Chapin HC, Rajendran V, \& Caplan MJ (2010) Polycystin-1 surface localization is stimulated by polycystin- 2 and cleavage at the $\mathrm{G}$ protein-coupled receptor proteolytic site. Mol Biol Cell 21(24):4338-4348

68. Riveline D, et al. (2001) Focal contacts as mechanosensors: externally applied local mechanical force induces growth of focal contacts by an mDial-dependent and ROCK-independent mechanism. J Cell Biol 153(6):1175-1186

69. Brevier J, Montero D, Svitkina T, \& Riveline D (2008) The asymmetric self-assembly mechanism of adherens junctions: a cellular push-pull unit. Phys Biol 5(1):016005

70. Brevier J, Vallade M, \& Riveline D (2007) Force-extension relationship of cell-cell contacts. Phys Rev Lett 98(26):268101

71. de Beco S, Perney, J.B., Coscoy, S., Amblard, F. (2015) Mechanosensitive adaptation of E-cadherin turnover across adherens junctions. . Plos One 10(6).

72. de Beco S, Amblard F, \& Coscoy S (2012) New insights into the regulation of Ecadherin distribution by endocytosis. Int Rev Cell Mol Biol 295:63-108

73. Smutny M, et al. (2011) Multicomponent Analysis of Junctional Movements Regulated by Myosin II Isoforms at the Epithelial Zonula Adherens. PLoS One 6(7):e22458

74. Reffay M, et al. (2011) Orientation and polarity in collectively migrating cell structures: statics and dynamics. Biophys J 100(11):2566-2575

75. Outeda P, et al. (2014) Polycystin signaling is required for directed endothelial cell migration and lymphatic development. Cell Rep 7(3):634-644

76. Castelli M, et al. (2015) Regulation of the microtubular cytoskeleton by Polycystin-1 favors focal adhesions turnover to modulate cell adhesion and migration. BMC Cell Biol 16(1):15

77. Park EY, et al. (2009) Cyst formation in kidney via B-Raf signaling in the PKD2 transgenic mice. J Biol Chem 284(11):7214-7222

78. Burtey S, et al. (2008) Overexpression of PKD2 in the mouse is associated with renal tubulopathy. Nephrol Dial Transplant 23(4):1157-1165

79. Thivierge C, et al. (2006) Overexpression of PKD1 causes polycystic kidney disease. Mol Cell Biol 26(4):1538-1548

80. Kurbegovic A, et al. (2010) Pkd1 transgenic mice: adult model of polycystic kidney disease with extrarenal and renal phenotypes. Hum Mol Genet 19(7):1174-1189

81. Esue O, Tseng Y, \& Wirtz D (2009) Alpha-actinin and filamin cooperatively enhance the stiffness of actin filament networks. PLoS One 4(2):e4411

82. Boca M, et al. (2006) Polycystin-1 induces resistance to apoptosis through the phosphatidylinositol 3-kinase/Akt signaling pathway. J Am Soc Nephrol 17(3):637647.

83. Ciobanasu C, Faivre B, \& Le Clainche C (2013) Integrating actin dynamics, mechanotransduction and integrin activation: the multiple functions of actin binding proteins in focal adhesions. Eur J Cell Biol 92(10-11):339-348 


\section{ACCEPTED MANUSCRIPT}

84. Ye N, et al. (2014) Direct observation of alpha-actinin tension and recruitment at focal adhesions during contact growth. Exp Cell Res 327(1):57-67

85. Hirata H, Tatsumi H, \& Sokabe M (2008) Zyxin emerges as a key player in the mechanotransduction at cell adhesive structures. Commun Integr Biol 1(2):192-195

86. Castelli M, et al. (2013) Polycystin-1 binds Par3/aPKC and controls convergent extension during renal tubular morphogenesis. Nat Commun 4:2658

87. Streets AJ, Wagner BE, Harris PC, Ward CJ, \& Ong AC (2009) Homophilic and heterophilic polycystin 1 interactions regulate E-cadherin recruitment and junction assembly in MDCK cells. J Cell Sci 122(Pt 9):1410-1417.

88. Clark K, et al. (2006) TRPM7, a novel regulator of actomyosin contractility and cell adhesion. Embo J 25(2):290-301.

89. Graziani A, et al. (Cell-cell contact formation governs $\mathrm{Ca} 2+$ signaling by TRPC4 in the vascular endothelium: evidence for a regulatory TRPC4-beta-catenin interaction. J Biol Chem 285(6):4213-4223.

\section{Highlights}

- Background Polycystins, which are mutated in Autosomal Dominant Polycystic Kidney Disease, are involved in mechanotransduction by primary cilia.

- Results Alpha-actinin recruitment upon mechanical stimulation of intercellular junctions, and multicellular behaviour, are perturbed in cells modified for polycystin 2 .

- Conclusion Polycystin 2 is involved in mechanotranduction in junctions.

- Significance In addition to its role in primary cilia, polycystin localization at intercellular contacts may play a role in cyst formation. 


\section{ACCEPTED MANUSCRIPT}

\section{a WT LifeAct-GFP}

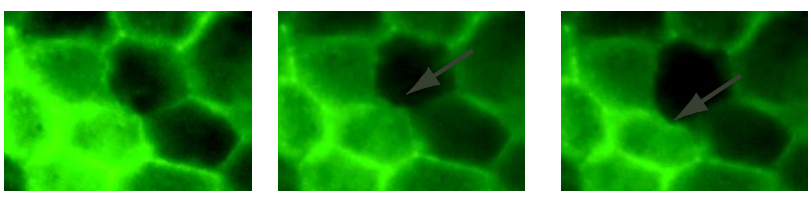

b wT $\alpha$-actinin-GFP
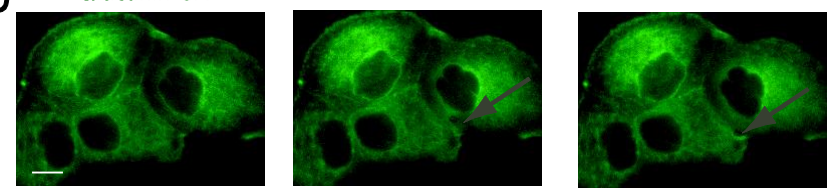

C lat-PC2 $\alpha$-actinin-GFP

d si-PC2 $\alpha$-actinin-GF
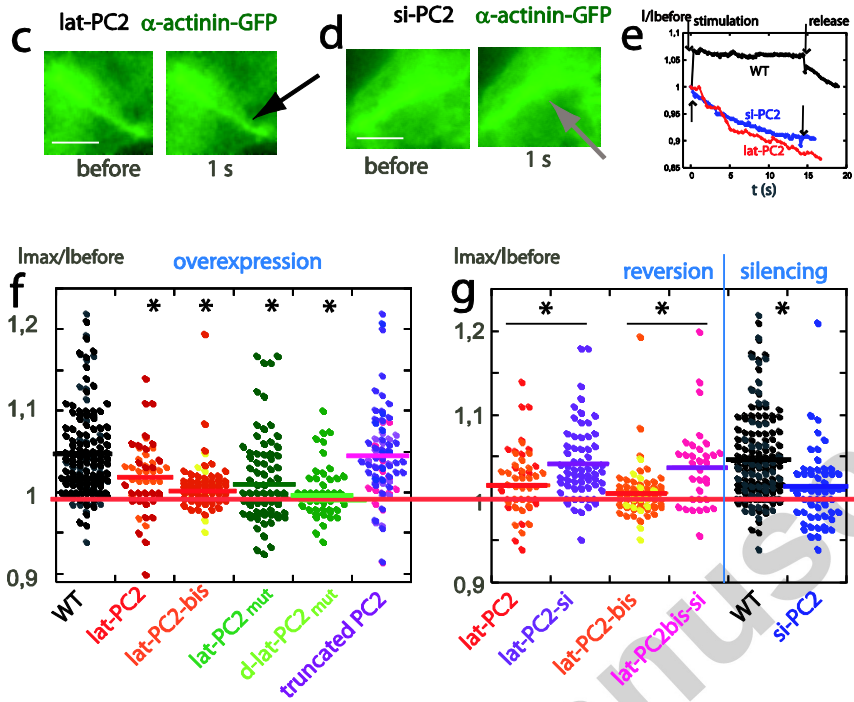

Imax/lbefore

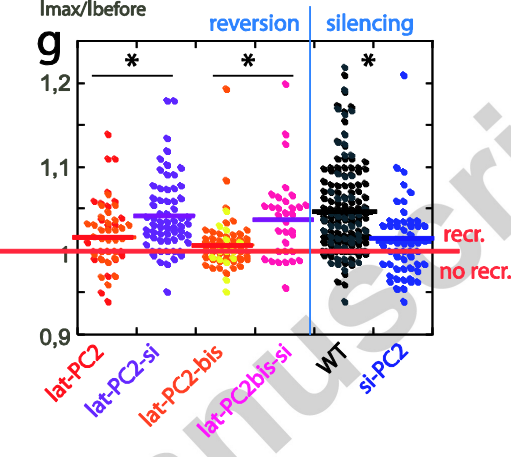




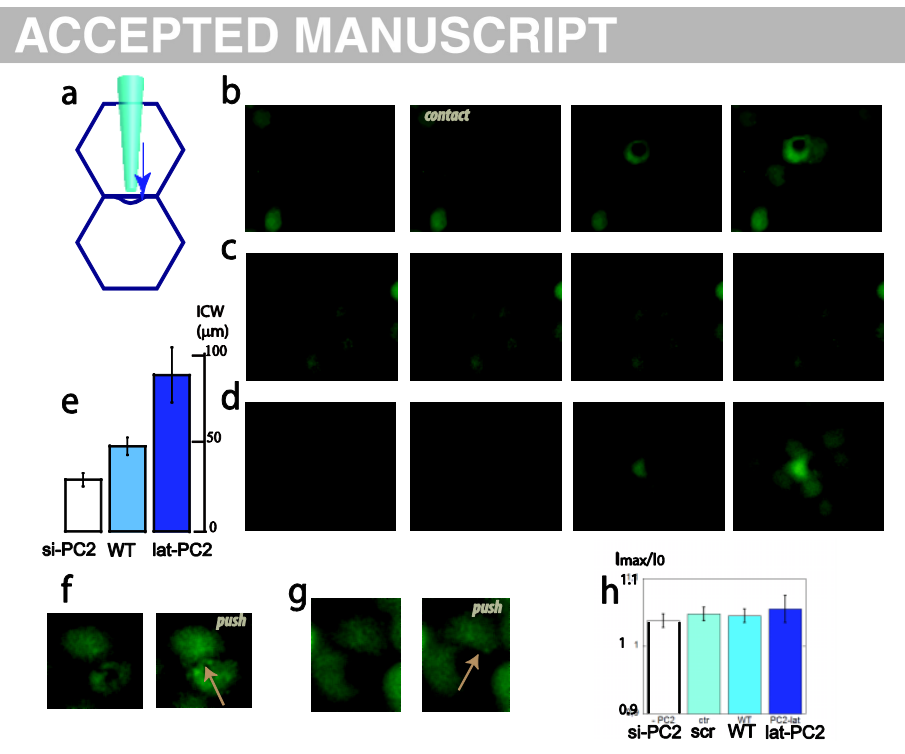

figure 2 


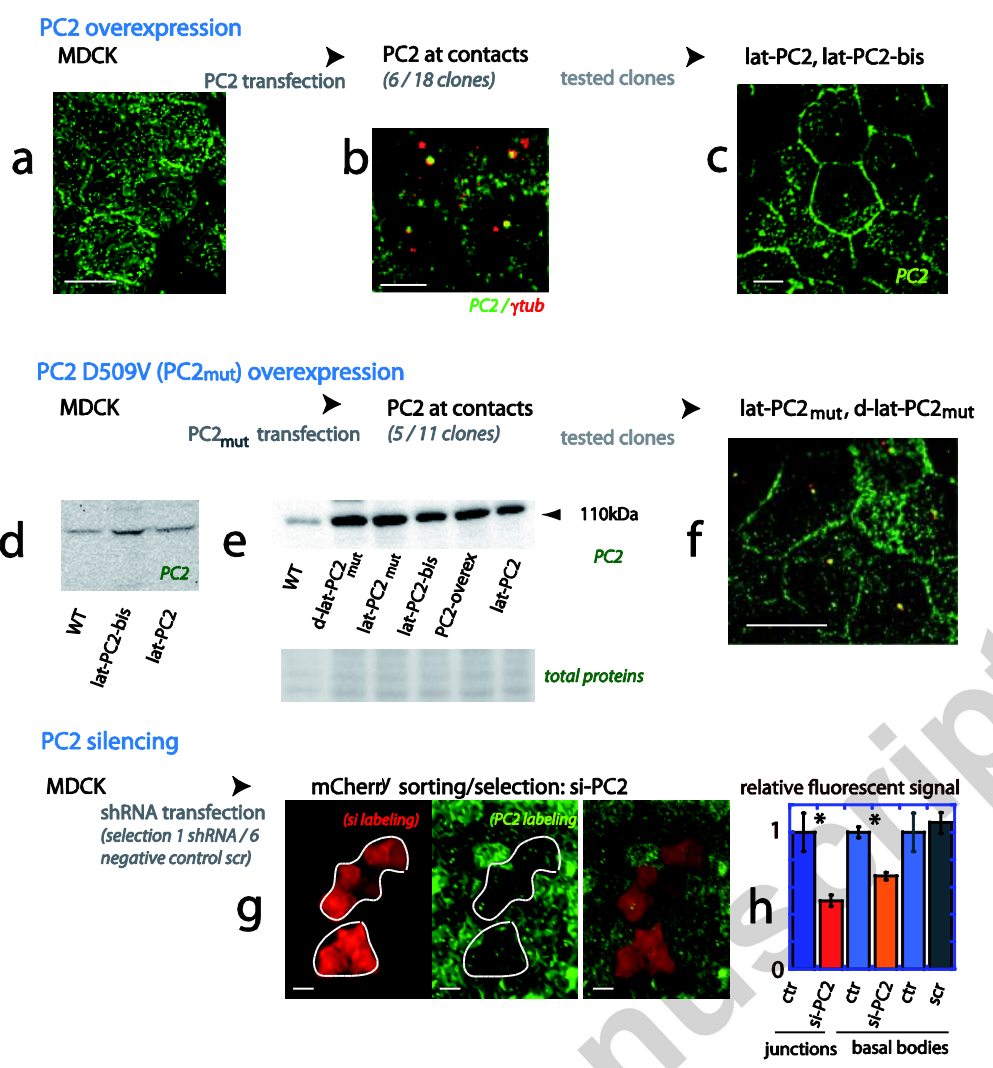


a

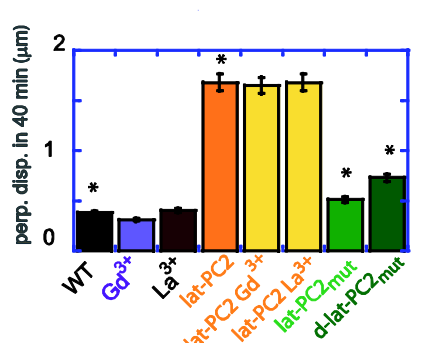

C

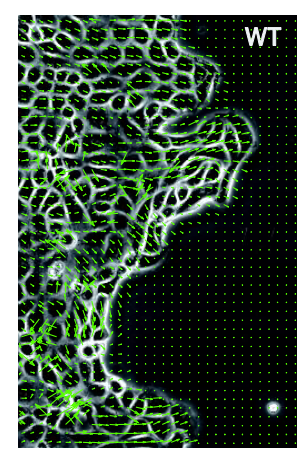

d b
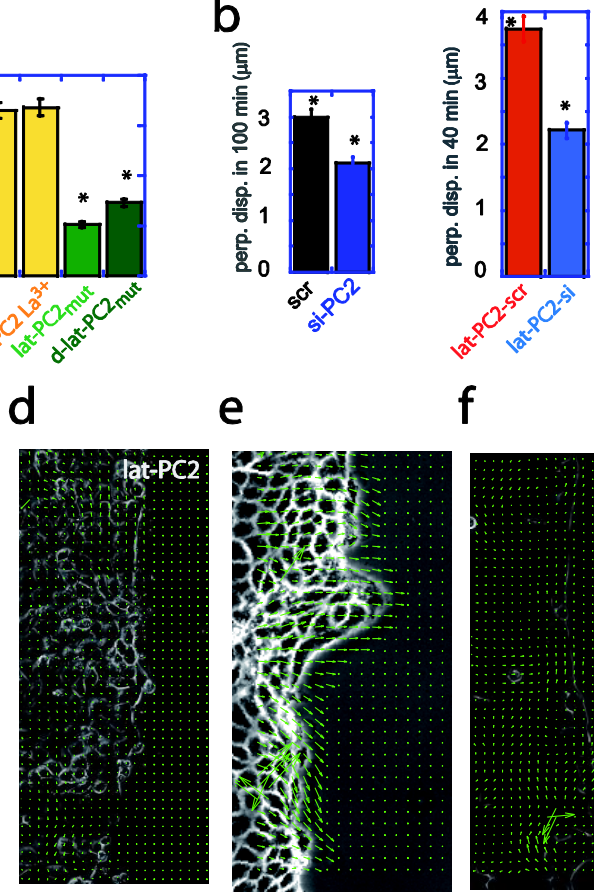

e

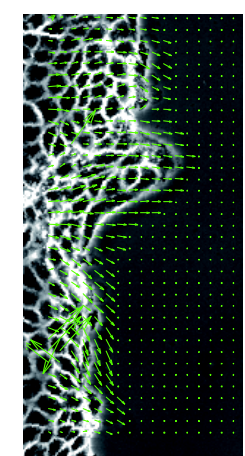

f

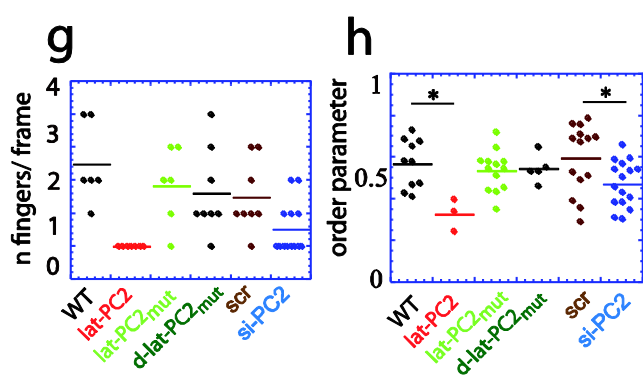

i

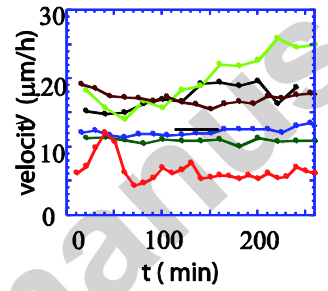

